
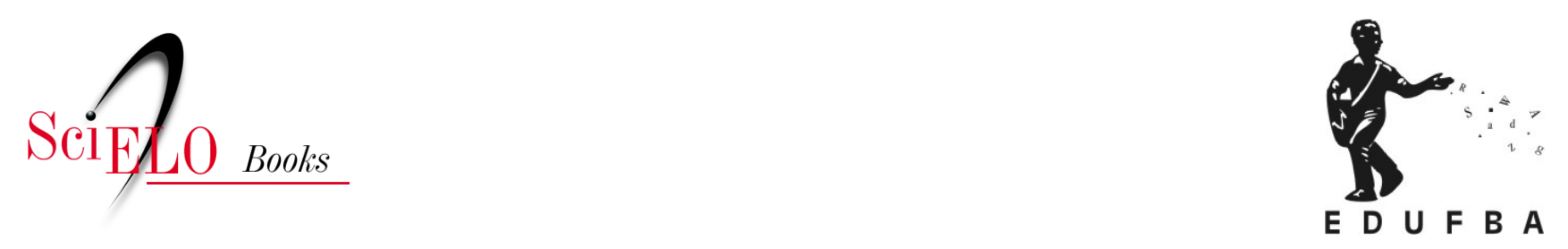

\title{
Politics \\ O espaço da saúde bucal coletiva: contribuições para compreensão da formulação e implementação das políticas de saúde bucal no Brasil
}

\author{
Catharina Leite Matos Soares \\ Jairnilson Paim \\ Thais Aranha Rossi \\ Sônia Chaves
}

\section{SciELO Books / SciELO Livros / SciELO Libros}

SOARES, C.L.M., PAIM, J., ROSSI, T.A., and CHAVES, S. O espaço da saúde bucal coletiva:

contribuições para compreensão da formulação e implementação das políticas de saúde bucal no Brasil. In: CHAVES, S.C.L. Política de saúde bucal no Brasil: teoria e prática [online]. Salvador: EDUFBA, 2016, pp. 137-170. ISBN 978-85-232-2029-7.

https://doi.org/10.7476/9788523220297.0006.

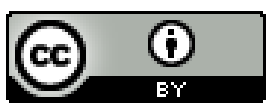

All the contents of this work, except where otherwise noted, is licensed under a Creative Commons Attribution 4.0 International license.

Todo o conteúdo deste trabalho, exceto quando houver ressalva, é publicado sob a licença Creative Commons Atribição 4.0. 


\section{O espaço da saúde bucal coletiva CONTRIBUIÇÕES PARA COMPREENSÃO DA FORMULAÇÃO E IMPLEMENTAÇÃO DAS POLÍTICAS DE SAÚDE BUCAL NO BRASIL}

Catharina Leite Matos Soares

Jairnilson Paim

Thais Aranha Rossi

Sônia Chaves

No final dos anos 1980, começa a circular nos serviços de saúde e depois no âmbito acadêmico a expressão "Saúde Bucal Coletiva" (SBC). (SOARES, 2014) Essa expressão surgiu no estado de São Paulo, particularmente no Instituto de Saúde de São Paulo. (BOTAZZO et al., 1988; SOARES, 2014) Embora venha sendo usado com frequência a partir desse período, há alguns equívocos quanto ao seu emprego, pois muitos trabalhos encontrados na literatura mostram que a SBC representa a antiga Odontologia Preventiva e Social (OPS). (CELESTE, WAMERLING, 2012; DIAS, NARVAI; REGO, 2008; )

Pretende-se com o presente texto apresentar ao leitor o processo histórico de emergência da SBC, entendendo-o como um espaço social, um espaço de lutas (BOURDIEU, 1994), bem como o aporte teórico sobre o qual se assenta a SBC e seus aspectos de distinção em relação às correntes emanadas da odontologia no período da emergência da SBC. Pretende-se ainda apresentar uma discussão sobre o potencial da SBC para as políticas e as práticas de saúde bucal no Sistema Único de Saúde (SUS), entendendo o conceito de política de saúde no sentido que lhe é dado por Paim (2000) enquanto resposta social (ação ou 
omissão) de uma organização (como o Estado) diante das condições de saúde dos indivíduos e das populações e seus determinantes, bem como em relação à produção, distribuição, gestão e regulação de bens e serviços que afetam a saúde humana e o ambiente.

\section{Antecedentes}

A odontologia, desde as suas origens, articulou-se com a medicina, seus saberes e práticas, favorecendo a consolidação de uma prática odontológica centrada na doença e no doente, particularmente no processo curativo, na ação do cirurgião-dentista, especialista, cujas atividades eram desenvolvidas em ambiente clínico-cirúrgico individual. (BOTAZZO, 2000; NARVAI, 1994; WARMILING, 2009)

Essa forma de conceber o processo saúde doença bucal favoreceu uma prática privada da odontologia, que veio a se consolidar no serviço público brasileiro por meio da emergência e desenvolvimento da previdência social (SERRA, 1998), propiciando o aparecimento e desenvolvimento de uma "odontologia de mercado", expressão cunhada por Narvai em 1994. A odontologia de mercado caracteriza-se pela livre escolha e definição de preços com base no mercado, destacando-se a vinculação com os detentores do poder político-econômico. (NARVAI, 1994)

Em São Paulo, surge o Programa Dentário Escolar e o Departamento de Odontologia Sanitária desse mesmo estado, vinculado à Secretaria Estadual de Educação. Essa seção representou um importante setor de práticas de odontologia escolar e anos depois se transformou em Programa Estadual de Saúde do Escolar. (SOARES, 2014) Narvai (2006) aponta que a odontologia sanitária fracassou no rompimento com a odontologia de mercado, ou seja, a prática centrada no atendimento ao indivíduo doente e restrito ao ambiente clínico cirúrgico.

Nesses anos 1950, diversos movimentos ditos contra-hegemônicos apareceram no cenário brasileiro como a odontologia sanitária, odontologia preventiva, odontologia social, odontologia simplificada, odontologia comunitária e odontologia integral. (NARVAI, 1994)

A odontologia sanitária é entendida como uma disciplina de saúde pública, que tem como objeto a saúde oral da comunidade. (CHAVES, 1986) Suas ideias tomam por referência a saúde pública norte-americana, exercendo sua prática sobre os problemas de saúde das comunidades e considerando como agente 
principal o sanitarista, que teria como paciente a comunidade, a coletividade ou o corpo político. (CHAVES,1986) Caracterizou-se por introduzir duas práticas de saúde bucal fundamentais no Brasil: o sistema incremental e a utilização do flúor como medida populacional. (NARVAI, 1994)

O sistema incremental foi a principal ferramenta utilizada pela odontologia sanitária para diagnosticar os problemas de saúde oral nas comunidades e caracterizava-se por um método de trabalho que visava o completo atendimento dental de uma dada população, eliminando suas necessidades acumuladas e, posteriormente, mantendo-as sob controle, segundo critérios de prioridade quanto à idade e aos problemas. (NARVAI, 2006)

Em 1951, aqui no Brasil, incorporou-se ao Serviço Especial de Saúde Pública (SESP), a Secção de Odontologia Sanitária, que passa a desenvolver atividades complementares às atividades assistenciais da previdência social, enquanto práticas odontológicas voltadas para escolares. (NARVAI, 1994) Esses programas contavam com a participação de engenheiros e médicos sanitaristas que já utilizavam essa terminologia em saúde pública, oriundos de um programa de cooperação entre o Brasil e os Estados Unidos. Seus programas enfatizavam tratamento das crianças em idade escolar.

O primeiro manual impresso com Normas Técnicas de Odontologia Sanitária foi editado pela Fundação SESP (FSESP) em 1963, no Rio de Janeiro. A política de cunho nacional trazia o atendimento prioritário aos escolares, com possibilidade de considerar alguns casos especiais para atendimento a gestantes e outros, uso de consultórios semiportáteis, utilização de pessoal auxiliar e alterações no sistema incremental original. (FSESP, 1963) Deram origem também no Brasil na experiência piloto em Aymorés, Minas Gerais e depois outros programas com essa concepção.

A chamada odontologia escolar é um modelo de prática odontológica bastante conhecido no setor público, tendo sido iniciada no Brasil com o sistema incremental. (FRAZÃO; NARVAI, 2008) O Manual de odontologia sanitária publicado por Mário Chaves, em 1960, é obra de referência para o modelo escolar e sistematizou um conjunto de medidas para intervenção na saúde pública, especificamente na odontologia. (FRAZÃO; NARVAI, 2008)

Já a OPS, relaciona-se com a medicina preventiva, desenvolvida nas escolas médicas norte-americanas (GARCIA, 1972), cuja criação de disciplinas específicas influenciou em seguida a América Latina. Esse fenômeno, no âmbito odontológico, ocorre no Brasil na década de 1970, resultando na criação dos Departamentos 
de Odontologia Preventiva e Social nas universidades brasileiras, impulsionado por um conjunto de seminários promovidos pela Organização Pan-Americana de Saúde (OPAS) com o apoio da Fundação Kellogg. (CASOTTI, 2009; NARVAI, 1994; QUEIROZ E DOURADO, 2009) Embora a OPS tenha sido influenciada pela medicina preventiva norte-americana, particularmente no Brasil, encontra respaldo nos estudos da cariologia realizados nos países escandinavos e culminou com a fundação de entidade denominada Associação Brasileira de Odontologia Preventiva (ABOPREV), em 1981. (NARVAI, 2006) Introduziu um arsenal de tecnologias no serviço público, tais como: dentifrícios fluoretados, uso massivo do flúor gel, selantes, entre outros, encontrando legitimação no mercado de produtos odontológicos. (SOARES, 2014)

Paralelo ao desenvolvimento da OPS no Brasil, ganha corpo a odontologia simplificada, que compreende uma prática profissional, a qual através da padronização, da diminuição dos passos e elementos e eliminação dos supérfluos, visava tornar mais simples e barata a odontologia, sem haver alteração da qualidade dos trabalhos, como também mais produtiva (MENDES, 1985; NARVAI, 1994), de modo que pudesse utilizar-se em trabalhos comunitários, podendo encontrar-se na literatura como "odontologia comunitária”. (NARVAI, 1994) Seu desenvolvimento no Brasil relaciona-se com a modernização do ensino odontológico coordenado também pela OPAS, cujas experiências docente-assistenciais em curso na América Latina possibilitaram a reflexão e teorização da odontologia simplificada. (SOARES, 2014)

Ademais, a simplificação do equipamento e espaço físico e a racionalização do trabalho odontológico eram elementos importantes na busca pelo aumento da produtividade. (FERREIRA, 1985) Nesse sentido, a técnica previa "máxima" utilização de pessoal auxiliar, mudanças no equipamentos odontológicos e espaços mais compactos e eficientes para o tratamento. (FERREIRA, 1985)

A principal experiência brasileira na prática da odontologia simplificada foi desenvolvida em Brasília, por Sérgio Pereira, responsável pela constituição do Programa Integrado de Saúde Escolar (PISE) 1 do Distrito Federal. (SOARES, 2014) O PISE é citado como um programa de impacto da odontologia simplificada (UCHOA, 1985) e de importância histórica. (SILVEIRA et al., 2002) Ele foi implementado no final de 1970, com a proposta de clínicas móveis nas escolas, numa equipe composta por dois dentistas e quatro técnicos em higiene

1 Informação disponível em site da Secretaria de Educação do Distrito Federal. Disponível em: http:// www.se.df.gov.br/?page_id=434. Acesso em: 5 set. 2013. 
dental. O programa centrava sua atenção nos dentes permanentes, seguindo também fundamentos do sistema incremental, mas a posteriori passou a incluir os dentes decíduos. (SILVEIRA FILHO et al., 2002) O Pise promovia ações voltadas para a saúde dos alunos da educação infantil e do ensino fundamental da rede pública do Distrito Federal. Prestava assistência médica e odontológica aos estudantes, com vistas a contribuir para a melhoria de seu desempenho escolar. (SOARES,2014) Além do PISE, cita-se o Programa Integrada de Ações de Saúde e Saneamento, em todo território nacional, que revia fluoretação das águas, aplicação tópica de flúor via bochechos, adequação de recursos físicos e humanos com ênfase para o atendimento escolar e implementação de unidades elementares, através de pessoal técnico, em localidades sem acesso aos serviços odontológicos. (PINTO, 1993)

A simplificação do atendimento, que se originou da corrente teórica da odontologia simplificada, era apontada como uma das alternativas para solucionar os problemas crescentes que os dentistas vinham enfrentando de mercado de trabalho. Foram feitas muitas críticas ao modelo como extremamente limitado, pois erigia-se como apêndice à odontologia tradicional, destinada às classes sociais marginalizadas, além disso, tratava da importância da prevenção, mas priorizava a prática curativa. (MENDES; MARCOS, 1985; NARVAI, 2002)

A implementação da odontologia simplificada no Brasil gerou o dilema quantidade versus qualidade, além de ser acusada de "extremamente limitada" por não questionar o modelo científico ou flexneriano, e possibilitou, pela crítica a esse fato, a emergência de outra versão dessa corrente, denominada de “odontologia integral”. (MENDES; MARCOS, 1985) Essa corrente crítica nasceu como consequência da adesão do Departamento de Odontologia da Universidade Católica de Minas Gerais ao Programa de Inovações em Ensino e Serviços Odontológicos, viabilizado pela Fundação Kellog, no âmbito do movimento de reorientação do ensino odontológico, corrente essa que já surge sob a dupla influência do processo de simplificação e também do desenvolvimento da prevenção odontológica no Brasil. (SOARES,2014)

Segundo Mendes (1986), a odontologia integral seria então um marco conceitual alternativo às práticas oriundas da odontologia científica e estaria articulado ao projeto transformador da sociedade denominado de Reforma Sanitária Brasileira. Nega dialeticamente a odontologia simplificada à medida que a incorpora como essencial para a extensão de cobertura, dando à tecnologia o status necessário e assume a prevenção, em sua versão ampla, como elemento 
constitutivo da prática profissional, articulado à desmonopolização do saber odontológico, e introduzindo o repasse do conhecimento técnico e científico à sociedade. A odontologia integral propunha reverter a concepção dita flexneriana e considerava como preparo inicial o conjunto de atos cirúrgico-restauradores para restabelecer a integridade do sistema estomatognático e, a partir desse equilíbrio recomposto, dar sequência ao conjunto de procedimentos preventivos para manter a "saúde restaurada". (MENDES, 1985) Entendia que esse processo de modernização da prática começaria a incidir no ensino e refletiria, por conseguinte na prática odontológica. (MENDES, 1996)

Através do desenvolvimento desse projeto, a Pontifícia Universidade Católica de Minas Gerais, em 1983, celebra um convênio de experiência docente-assistencial com o Instituto Nacional de Assistência Médica da Previdência Social (Inamps), através do seu coordenador específico de odontologia, Paulo Freire. A experiência serviu de modelo para muitas faculdades de odontologia e reduziu a quantidade de extrações realizadas nesse modelo em comparação ao praticado nos serviços do Inamps.

A sua origem estaria vinculada ao processo de modernização odontológica viabilizado pela OPAS em parceria com a Fundação Kellogg e possibilitou o desenvolvimento no Brasil da odontologia simplificada e da sua versão mais crítica, a odontologia integral. A crítica a essas concepções e seu processo de implementação foi fundamental para o aparecimento da SBC no Brasil, embora toda uma tendência internacional para a incorporação da odontologia preventiva pela influência da medicina preventiva norte-americana tenha sido empreendida pela OPS e pela Fundação Kellogg, com a orientação inclusive de agentes brasileiros.

\section{O espaço de luta da saúde bucal e a constituição da SBC no Brasil: aspectos históricos da sua emergência}

A incorporação da OPS consolidou-se nos anos 1980, com aparecimento da Associação Brasileira de Odontologia Preventiva (Aboprev), que atualmente denomina-se de Associação Brasileira de Odontologia de Promoção da Saúde. A Aboprev incorpora a experiência e a produção científica dos países escandinavos no que tange à cárie e doença periodontal, bem como suas bases etiológicas, além das experiências de prevenção aplicada à saúde pública naqueles países, cujos níveis de cárie haviam reduzido com a introdução das tecnologias preventivas nos serviços de saúde. A disseminação desse conhecimento sobre 
a etiologia da cárie e da doença periodontal pela Aboprev ganha robustez à medida que se evidencia o uso das tecnologias preventivas também para o setor privado. (SOARES, 2014)

Membros da Aboprev à época, com capital científico e simbólico já acumulado, tiveram papel fundamental na produção crítica que a Aboprev desenvolveu acerca de produtos odontológicos e também na formulação de políticas de saúde bucal no âmbito da prevenção. Naquele momento, destacam-se duas ações fundamentais: o fortalecimento da ação de fluoretação das águas de abastecimento público e a vigilância dos cremes dentais. Sua fundação foi significativa para o espaço de luta da saúde bucal e possibilitou a emergência de um espaço social ao interior do campo odontológico, que vai agregar muitos agentes preocupados com a falência do modelo curativo da odontologia de mercado. (SOARES, 2014)

A análise da OPS mostra uma composição mista que agregava professores e pesquisadores, tanto da área básica como aqueles originalmente da saúde pública tradicional. As principais influências teóricas nesse espaço foram aquelas de origem escandinava e que tratavam da "nova cariologia" e as estratégias de prevenção para o controle da cárie e da doença periodontal. Ainda que agregasse na área à ideia da odontologia social, a visão escandinava desenvolveu-se como concepção dominante, assumindo inclusive a hegemonia no campo odontológico entre as concepções que eram disputadas no referido espaço, embora subalterna a odontologia de mercado. Como concepção dominante, exerceu influência nas políticas e práticas de saúde bucal, notadamente a normatização dos cremes dentais no Brasil e a definição dos argumentos que foram definitivos para a expansão da fluoretação das águas de abastecimento público. Alguns dirigentes da Aboprev compunham o comitê de assessoramento da Divisão Nacional de Saúde Bucal, em 1989, e influenciaram algumas respostas do Estado brasileiro quanto à fluoretação dos cremes dentais e posteriormente dos enxaguatórios bucais, através da Portaria n. ${ }^{\circ}$ 17, da Divisão Nacional de Vigilância Sanitária de Medicamento, de 25 de outubro de 1989, e da Portaria n. ${ }^{\circ}$ 22, da Secretaria Nacional de Vigilância Sanitária, de 20 de dezembro de 1989.

Entre as principais contribuições Aboprev para as políticas de saúde bucal no Brasil, é possível identificar alguns pontos fundamentais:

a. Auxiliou na fundação de uma concepção voltada para a prevenção das doenças bucais em detrimento da odontologia privada ou de mercado e distinta da visão americana que vinha sendo discutida no Brasil; 
b. Auxiliou na formulação de políticas, especialmente da fluoretação das águas de abastecimento público e a regulamentação das normas para a vigilância e comercialização dos cremes dentais no Brasil;

c. Atuou no rompimento do modelo dentário escolar sespiano, por meio da inserção de outra visão sobre a cárie dental, mas manteve a concepção de geração perdida;

d. Influenciou as políticas de saúde bucal de caráter preventivo;

e. Fomentou a crítica ao mercado odontológico, ainda que as contradições tenham possibilitado um fenômeno denominado preventivismo, fenômeno que corresponde ao "abuso" das tecnologias preventivas, com valor de mercado, em nome do qual as atividades assistenciais chegavam a se desestruturar.

f. Auxiliou a inserção de medidas preventivas no setor privado, ainda que essa incorporação se deva à transformação dessas em mercadoria.

g. Desenvolveu duas subáreas da odontologia: a cariologia e a periodontia no Brasil.

Nos anos 1990, com o avanço da Reforma Sanitária Brasileira (RSB) e a inclusão de novos temas no espaço social em questão, a Aboprev, como entidade coletiva, reduz a sua capacidade de influenciar as políticas e práticas de saúde bucal. Nesse particular, passa-se a discutir a democratização, a descentralização, a municipalização, a integração de recursos, a criação de um SUS entre outras questões que se tratavam de temas próprios da saúde coletiva e não do campo odontológico. Nesse espaço, que tinha como concepção dominante o controle e tratamento preventivo da cárie e da doença periodontal, conviveu de modo dominado, uma concepção que nasce nesse período atrelado a um grupo de agentes com prática de saúde pública mais orgânica e cuja aproximação com a RSB levou a problematizar certas questões desse espaço social híbrido e a pensar em fundar um espaço novo. Esse grupo, considerado dominado, que implementava as políticas de saúde bucal nos diversos estado e municípios do país, envolveu-se em vários movimentos no espaço social e vieram a disputar suas ideias com a concepção dominante até então, representada pela Aboprev. (SOARES, 2014)

O primeiro deles foi o Encontro Científico dos Estudantes de Odontologia (Eceo), retomado em 1979, pois fora suspenso pelo Golpe Militar de 1964. Sua 
origem remonta ao ano de 1954 e foi responsável pela conformação da União Nacional dos Estudantes, que envolviam diretórios acadêmicos dos quais participaram vários dos agentes engajados nas lutas pela saúde bucal pública. Tinha como propósito principal fomentar nos estudantes de odontologia a capacidade crítica acerca das questões fundamentais no campo odontológico, especialmente a prática odontológica hegemônica. (SERRA, 1998; SOARES, 2014)

No ano de 1984, surge o Movimento Brasileiro de Renovação Odontológica (MBRO). Correspondeu a um movimento social da categoria odontológica a fim de democratizar as entidades odontológicas e representava o movimento de Reforma Sanitária Brasileira ao interior da odontologia. Teve como precursor o MBROESP, movimento dos odontologistas do estado de São Paulo, que visava inserir-se nas entidades odontológicas, notadamente Conselho Regional de Odontologia de São Paulo (CROSP), Associação Paulista de Cirurgiões Dentistas (APCD) e Sindicato dos Odontologistas. (SOARES, 2014)

Suas principais pautas foram: a luta pelas liberdades políticas, a posição contrária à mercantilização da prestação de serviços odontológicos, a defesa da expansão desses serviços pela municipalização, o controle das instituições pela população organizada, aumento de recursos para a assistência odontológica com uso de tecnologia nacional, recursos humanos adequados à realidade socioeconômica e epidemiológica do país e sua justa remuneração, defesa do ensino público e gratuito em todos os níveis e campos do saber odontológico e a democratização das entidades odontológicas. Menciona ainda que, nas diretrizes do MBRO, divulgadas em 1985, constavam a luta permanente por liberdades políticas, a implantação de um SUS responsável pelos serviços odontológicos em todo o país, o repúdio frontal a qualquer tipo de mercantilização dos serviços odontológicos, ênfase na municipalização e no controle das instituições pela população organizada, a utilização de recursos humanos, materiais e financeiros para desenvolver uma odontologia adequada às necessidades socioeconômicas e epidemiológicas do país, a defesa de tecnologia nacional na pesquisa e produção de equipamentos, materiais e medicamentos de uso odontológico, a defesa do ensino público e gratuito em todos os campos do saber odontológico, a luta pelo fortalecimento e democratização das entidades odontológicas e o estímulo à promoção e participação das discussões acerca da prática odontológica brasileira. (SOARES, 2014)

O MBRO também representou um espaço de militância e formação política dos cirurgiões dentistas que vieram a se envolver nos serviços públicos de saú- 
de (Figura 1). No período das eleições diretas para governadores, esse movimento propiciou a ocupação de posições nas várias coordenações municipais e estaduais de saúde bucal por muitos dos seus militantes do movimento sanitário, cujas dificuldades com a implementação da Política de Saúde Bucal levaram à discussão coletiva dessas questões. A Política de Saúde Bucal representou o dispositivo para construir a crítica mais sistematizada ao campo odontológico, uma crítica de origem nos serviços de saúde. Sua influência cresce à medida que se articula com as questões mais gerais da Reforma Sanitária e, como consequência dessa articulação, em 1986, foi publicada a revista específica do Centro Brasileiro de Estudos em Saúde (Cebes) sobre as "questões odontológicas" (Figura 2).

Figura 1 - Boletim do MBRO de setembro de 1985

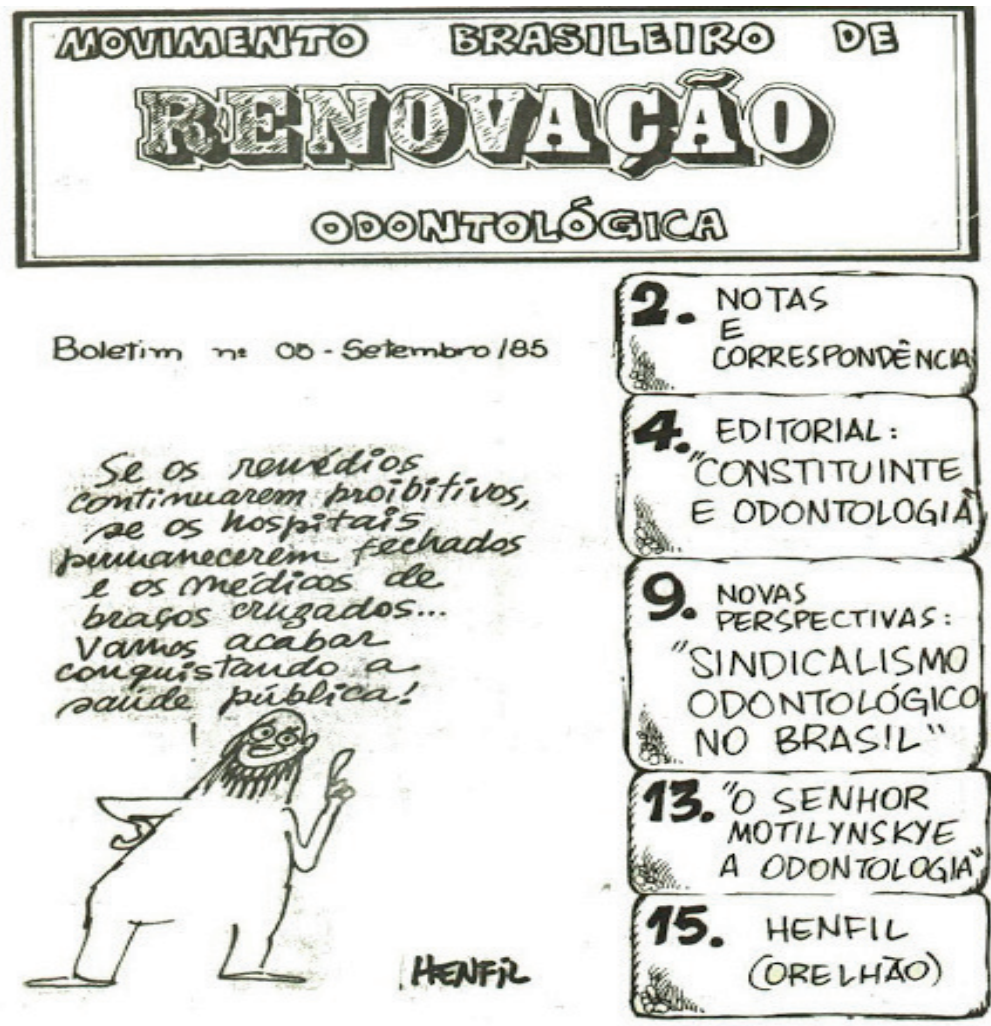

Fonte: (O) Dentista e o mundo do trabalho (2011). 
Figura 2 - Capa e expediente da revista Saúde em debate

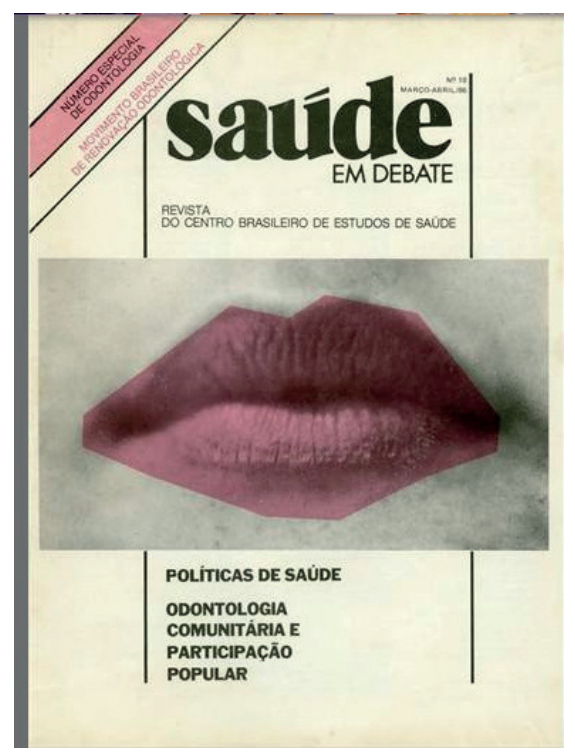

\section{Editorial}

O Centro Brasileiro de Estudos de Saúde e o Movimento Brasileiro de Renovação Odontológica colocam em circulação este número especial da REVISTA DO CEBES, dedicado à Odontologia.

A importância que, entre nós, o estudo das questões gerais da saúde tem merecido nos últimos anos, e a emergência de uma Sociologia vinculada à saúde bucal, justificam a necessidade desta edição.

Talvez para muitos colegas o conteúdo da Revista cause estranheza. As publicações especializadas que temos à nossa disposição são em geral publicações técnicas com forte inclinação para os aspectos biológicos - clínicos ou labororatoriais.

Julgamos existir uam lacuna entre a formação universitária - científica e técnica em sua essência - e a realidade social na qual estamos inseridos.

Faz-se, portanto, necessário que a investigação em saúde bucal se volte para essa realidade e que, incorporando as ciências sociais e sua metodologia de análise, busque equacionar os problemas de saúde oral da comunidade e analise as relações que a cirurgia-dentista com ela mantém.

É nosso desejo, sinceramente, que este número da Revista do CEBES ajude um pouco nesta tarefa.

Movimento Brasileiro de Renovação Odontológica

Dezembro de 1985.

Fonte: Saúde em Debate (1986). 
As dificuldades na implementação das políticas de saúde bucal nos níveis locais e estaduais levaram os agentes responsáveis por elas a criarem um fórum de debate onde as questões relativas ao contexto do sistema público de saúde fossem discutidas. Esse fórum foi denominado de Encontro Nacional dos Administradores e Técnicos dos Serviços Públicos Odontológicos (Enatespo), em 1986, e reunia lideranças envolvidas na luta pela saúde bucal pública e de qualidade. Os Enatespos acontecem até os dias de hoje e permanecem como um espaço de discussão das pautas dos serviços de saúde. Incorporou a partir da década de 1990 o Congresso de Saúde Bucal Coletiva, fora dos moldes acadêmicos tradicionais, embora possuam a contribuição de agentes do campo científico. (SOARES, 2014)

Em 1988, mais uma iniciativa para a politização do campo odontológico se concretiza na fundação de Federação Interestadual de Odontologistas (FIO). Essa entidade corresponde a uma entidade sindical para representação dos interesses da corporação odontológica, criada à época sob o argumento de que as demais entidades odontológicas eram mera formalidade. Agregaram vários dirigentes de sindicato odontológico, integrado aos demais trabalhadores de saúde e foi um importante veículo de formação política e técnica desses dirigentes. (SOARES, 2014) Sua fundação esteve relacionada a uma conjuntura nacional de grande mobilização política e social, vindo de uma ampla participação da sociedade civil e dos trabalhadores em especial, na Assembleia Nacional Constituinte. Sua fundação ocorre às vésperas das primeiras eleições diretas pós-Golpe Militar para presidente da República, que ocorreriam no ano seguinte (1989). Surgiu da necessidade de se construir uma entidade sindical que representasse os interesses mais legítimos da categoria odontológica, evoluindo de uma representação nacional meramente burocrática e formal, até então existente, distante das lutas da categoria. (SOARES, 2014)

Associaram-se, de imediato, a esse projeto vários sindicatos de odontologistas (Distrito Federal, Goiás, Espírito Santo, Minas Gerais, Mato Grosso do Sul, Mato Grosso, Rio de Janeiro, Rio Grande do Norte e Manaus) que tinham um compromisso político com a construção de um novo sindicalismo odontológico, integrado às lutas dos demais profissionais de saúde e trabalhadores brasileiros. Teve um papel importante em diversas ações na área de saúde, e no espaço social específico aqui discutido: atuou na luta pela aprovação das leis orgânicas da saúde e nas eleições diretas para presidente de 1989; na elaboração da tabela nacional de convênios e credenciamentos e em muitas mobilizações 
que culminaram em acordos salariais que envolveram sindicatos dos odontologistas. Também participou das Conferências Nacionais de Saúde e de Saúde Bucal e nas lutas pelo SUS. Destacou-se também nas lutas que culminaram com o impeachment do presidente Collor e outras conquistas para a categoria odontológica, tais como: duplo vínculo e equacionamento da jornada de trabalho. (SOARES, 2014)

Vale mencionar que, entre os papéis exercidos pela FIO, destacaram-se: a formação técnica e política de muitos coordenadores de saúde bucal no Brasil, bem como na influência das políticas de saúde bucal à época; a atuação no parlamento e nas negociações salariais com os setores público e privado; a articulação com as demais entidades odontológicas em todas as pautas que são do interesse dos cirurgiões-dentistas; a parceria com os demais profissionais de saúde e outras categorias dos trabalhadores brasileiros pela construção de uma sociedade em que todos tenham direito a condições dignas de saúde; além de possuir uma atuação na representação nos conselhos de saúde. (SOARES, 2014)

Às mobilizações oriundas do MBRO, Eceos, Enatespo e FIO agregaram-se professores universitários, coordenadores, técnicos de saúde bucal e estudantes de odontologia que foram se envolvendo nos processos políticos mais amplos, como a Reforma Sanitária Brasileira. A ampliação desse movimento constituiu importantes polos críticos da saúde bucal em vários locais do país a exemplo de Brasília, São Paulo, Belo Horizonte e Curitiba, embora outros estados com menor vulto também tenham participado desse processo. Esse processo de politização e a defesa de uma bandeira de luta comum articulada aos movimentos, culminaram com a realização da $1^{\text {a }}$ Conferência Nacional de Saúde Bucal, em 1986, e suas respectivas etapas estaduais que, na discussão local, abarcou diversos agentes que atuaram como delegados na Conferência Nacional. (SOARES, 2014) Ademais, possibilitou a emergência de críticas ao ensino e as práticas odontológicas em curso.

Nesse evento, houve a discussão da situação de saúde bucal e dos principais problemas inerentes ao campo odontológicos. Entretanto, a principal reivindicação dessa conferência consistia na entrada da odontologia no SUS e no Movimento de Reforma Sanitária Brasileira. Essa conferência foi o marco para o processo de politização do campo odontológico, dada à magnitude, extensão e visibilidade que adquiriu. (SOARES, 2014) 
Já no final dos anos 1990, as críticas continuam a se processar, porém concentrando-se no preventivismo, fenômeno decorrente da exacerbação dos usos da odontologia preventiva, e do crescimento da influência da OPS, consoante inclusive com o crescimento da atuação da Aboprev no cenário brasileiro; e da incorporação das práticas de odontologia preventiva, seja nos serviços públicos, seja nos serviços privados, num contexto de implementação do SUS.

Pode-se afirmar que a década de 1980 foi decisiva para o desenvolvimento da crítica à odontologia, seu campo e suas práticas tradicionais. Conformou-se, à época, espaços de militância, de crítica e de reflexão que vão contribuir, na década seguinte, para a origem da SBC no Brasil. Houve refluxo do MBRO no início dos anos 1990, quando muitos dentistas integrantes do movimento passaram a ocupar posições no âmbito do Estado e deixaram de participar mais efetivamente desses espaços de militância. Alguns agentes atribuem essa desmobilização à emergência da FIO, instância formal de intervenção nas políticas de saúde bucal, que passa a influenciá-las. (SOARES, 2014)

Com a aproximação dos agentes de saúde bucal da Reforma Sanitária Brasileira, particularmente por meio do envolvimento com a fundação ou participação no Cebes, houve, por conseguinte, a aproximação com a Saúde Coletiva Brasileira, entendida como um movimento crítico que estabelecia rupturas com a saúde pública tradicional. Esse movimento crítico trazia também algumas reinvindicações tais como: a conformação de um sistema universal de saúde, democratização da saúde, direito à saúde, entre outras questões. Dessa aproximação, emergiram também as críticas às práticas de saúde bucal desenvolvidas no sistema público de saúde e a discussão de integração das práticas de saúde bucal no âmbito do SUS.

Como produto dessa inserção, vários agentes do antigo espaço da OPS vão se aproximando dos referenciais teóricos da saúde coletiva, naquele momento, prioritariamente baseados no materialismo histórico de Karl Marx. Por sua vez, essa aproximação, constituiu uma rede de relações que deram origem à SBC no Brasil. Essa origem pode ser atribuída também a aproximação de agentes dos serviços de saúde no estado de São Paulo e às discussões e debates realizados ao interior do Instituto de Saúde de São Paulo.

No período em que ocorreram eleições democráticas para governador, assume o governo estadual de São Paulo o governador Franco Montoro, e a Secretaria Estadual de Saúde passa a ser conduzida por João Yunes, professor da Faculdade de Saúde Pública da Universidade de São Paulo, pediatra, sanitarista, que 
por sua vez convida Paulo Capel Narvai para assumir a Coordenação de Saúde Bucal do estado de São Paulo. Sua assunção ao cargo possibilitou a articulação com os coordenadores municipais de saúde bucal para o compartilhamento dos problemas acerca dos serviços públicos de saúde bucal do estado e a aproximação com o Núcleo de Dentistas dos Sindicatos de São Paulo. A tônica desse governo era a desconstrução da lógica da odontologia escolar que imperou no serviço de saúde de São Paulo até então. (SOARES, 2014)

Em 1985, Paulo Capel sai da referida coordenação e vai para o Instituto de Saúde de São Paulo, onde também encontra Carlos Botazzo e outros agentes que se envolviam em debates críticos acerca das políticas, práticas e correntes teóricas em saúde bucal em curso nos serviços de saúde pública. Ou seja, constitui-se um grupo de agentes que protagoniza um conjunto de discussões que tinha como objeto "as práticas de saúde bucal nos serviços de saúde”, notadamente o foco nos escolares, a odontologia de mercado e a simplificação e suas modificações. Nesse local, passou a funcionar encontros periódicos de discussão do andamento do curso das Políticas de Saúde Bucal e das principais experiências em andamento. Nesse particular, destacaram-se: a experiência de simplificação coordenada por Sérgio Pereira em Brasília, a experiência de Minas Gerais com a odontologia integral liderada por Eugênio Vilaça e Badeia Marcos e o próprio Programa Estadual de Odontologia Escolar de São Paulo. (SOARES, 2014)

Os encontros no Instituto de Saúde representaram um espaço de crítica e de reflexão acerca da odontologia na prática pública. O primeiro produto concreto dessas críticas surge em 1988, em um texto preparado por Marco Manfredini, Paulo Capel, Paulo Frazão e o Carlos Botazzo, que utiliza o termo SBC e traz uma reflexão teórica e crítica acerca das correntes alternativas em odontologia, em especial à odontologia integral. (BOTAZZO et al, 1988) Esse texto específico acerca da SBC foi produzido pelos agentes paulistas para um curso de formação de pessoal auxiliar em odontologia. Nesse manuscrito, os autores debruçam-se fundamentalmente sobre a construção do conceito de saúde, para apontar a necessidade de intervenção sobre os determinantes sociais e especialmente sobre a prática da odontologia integral. A crítica às demais práticas de saúde bucal vão sendo incorporadas por esses agentes em outros textos posteriores do Instituto de Saúde. (SOARES, 2014)

A negação dos referenciais com o campo odontológico (NARVAI, 1994) e a reflexão crítica das práticas em serviços de saúde, mais especialmente da odon- 
tologia integral, é que deram as bases conceituais para a SBC, já que as bases políticas foram construídas no Eceo, MBRO, Enatespo e FIO. (SOARES, 2014)

Contribuíram para a emergência da SBC: a conjuntura política da democratização do país, que possibilitou a realização de eleições diretas para governos estaduais e, por conseguinte, a criação de espaços democráticos em vários estados, incluindo São Paulo, que já possuía grupos de sanitaristas nos seus quadros. A democratização da saúde permitiu a criação de vários grupos de resistência e luta, incluindo nesse bojo grupos de saúde bucal para a politização da odontologia e seus agentes. Também a implantação dos governos democráticos favoreceu a ocupação de coordenações de saúde bucal por egressos desse processo político ocorrido no âmbito odontológico, e, de modo muito particular, as discussões sobre a prática odontológica nos serviços de saúde realizada no Instituto de Saúde de São Paulo. Acresce-se a essas questões a aproximação dos agentes da SBC com outros agentes da saúde coletiva e com a Reforma Sanitária Brasileira, o que potencializou a reflexão dos agentes da saúde bucal. (SOARES, 2014)

\section{Saúde bucal coletiva, o que é isso afinal?}

Pode-se afirmar que a SBC é produto de um processo histórico de construção de uma práxis política desencadeada ao longo da década de 1980, de uma crítica às correntes odontológicas em curso no mesmo período e também uma proposta de intervenção sobre os problemas de saúde bucal da sociedade.

A proposta de prática odontológica voltada para o tratamento dentário restrito a crianças em idade escolar para o enfrentamento da cárie dentária pode ser entendida como um dos primeiros objetos de crítica. Esse modelo de prática odontológica orientava-se pelas ideias de odontologia sanitária e durante muito tempo foi a principal influência para a organização dos serviços de saúde bucal no Brasil. (NIKEL, 2008)

Apesar da crítica à odontologia sanitária e à implantação de serviços nessa direção, a SBC toma como referência a odontologia integral e a odontologia simplificada.

A odontologia integral pode ser entendida como uma versão crítica da odontologia simplificada, experimentada e teorizada pelo grupo acadêmico de Minas Gerais. A crítica processava-se, de um lado, sobre a odontologia simplificada, especialmente sobre a "excessiva simplificação" que conformou um programa voltado para pobres, com tecnologia simples para gente simples; e, do 
outro, sobre a odontologia científica que se expressava no "espelho" da medicina e tendia a parcelar o corpo entendendo-o como máquinas. (MENDES, 1986)

No caso da simplificação, o ocasionamento de certo dilema pelo desenvolvimento de sua prática odontológica traduzido em uma prática para pobres, com baixa qualidade e utilização da prevenção como retórica, tornou-se "apêndice" da prática tradicional. Estaria então fomentando uma prática odontológica que expressava o exercício de uma política social excludente, discriminatória e que consolidava a desigualdade entre classes sociais. (MENDES, 1986)

E, no caso da odontologia científica, suas características coadunam com o mecanicismo entendendo o corpo como máquina, coerente com o modo de produção dominante, reconhecendo a natureza biológica das doenças e suas causas; o individualismo elegendo o indivíduo como objeto da prática profissional e como responsável pela própria doença; a especialização por meio da fragmentação do processo de trabalho, que estimula a acumulação do capital; a exclusão de práticas alternativas, bem como a tecnificação do ato odontológico, concentrando-se na odontologia curativa tal qual a odontologia de mercado (NARVAI, 1994) e a excessiva especialização. (MENDES, 1986)

Essas críticas assentavam-se nas ideias veiculadas no Movimento de Reforma Sanitária Brasileira que trazia um conjunto de proposições tendo em conta as transformações da sociedade e em particular um sistema de saúde universal e com princípios de justiça social. (ESCOREL, 1998; PAIM,2008) Daí que esse modelo de prática odontológica em curso torna-se incoerente com os seus princípios.

A proposta da odontologia integral (MENDES, 1986) apresentava-se como uma proposta consoante com os princípios da Reforma Sanitária Brasileira, entendendo-a como um projeto democrático para a saúde e alternativo ao projeto sanitário hegemônico. Este se expressava no Sistema Nacional de Saúde e nas práticas curativas de saúde derivadas desse sistema. Nesse particular, entende o conceito amplo de saúde evitando a sua redução às práticas médico-odontológicas preventivas, curativas ou reabilitadoras, ofertadas nos serviços de saúde, sendo, portanto, resultante da ação articulada dos diferentes setores como educação, alimentação e nutrição, lazer, esporte, terra, transporte entre outros.

A odontologia integral coloca-se como uma possibilidade teórica e prática substitutiva à odontologia científica, admitindo três pilares centrais: a) atitude preventiva; b) simplificação e adequação de atos e técnicas, equipamentos, materiais, métodos e sistemas de trabalho; e c) desmonopolização do saber e do 
fazer pela educação, instrução e repasse do conhecimento à sociedade. Cabe salientar que essa concepção busca inserir a questão da prevenção ${ }^{2}$ numa perspectiva ampliada, evitando a dicotomia curativo versus preventivo. (MENDES, 1986)

Ao apresentar esses elementos críticos, Mendes (1986) aponta os seguintes componentes estruturais e ideológicos para a odontologia integral:

- Coletivismo - consiste na integração das práticas promocionais, preventivas e curativas, recompondo a integralidade do ato odontológico, sob a hegemonia do preventivo e do promocional;

- Descentralização da atenção odontológica - substitui a concentração de recursos propostos pela odontologia científica pela ideia de níveis de atenção; pensa-se na universalização do acesso a todos os níveis e no deslocamento do poder decisório para a periferia do sistema;

- Inclusão de práticas odontológicas alternativas - capta no discurso popular as práticas odontológicas alternativas para integrá-las dialeticamente ao discurso oficial.

- Equipe de saúde - a equipe odontológica substitui o especialismo, onde se distribuirá as funções odontológicas por distintos recursos humanos, incluindo a comunidade.

- Tecnologia apropriada - a sofisticação é substituída pelo uso de tecnologia apropriada para os níveis de atenção a um custo mínimo;

- Participação comunitária - Participação ativa da comunidade nos processos educacionais e da prática odontológica, como condição básica para a sua democratização.

A odontologia integral seria então uma prática, ecologicamente orientada, alternativa à prática odontológica flexneriana, que tem como objetivo último a manutenção da saúde, e que é caracterizada pela natureza coletiva do seu objeto, pela ênfase na prevenção no seu significado mais amplo, pela simplificação dos elementos da prática profissional, com a utilização intensiva de tecnologia

\footnotetext{
2 Para Arouca (2003, p. 36), a atitude preventiva consistia em movimento ideológico que, partindo da crítica à prática médica, propõe uma mudança, baseada na transformação da atitude médica para com o paciente, sua família e a comunidade.
} 
apropriada e pela desmonopolização do saber odontológico. (MENES, 1986; p. 545)

De fato, a odontologia integral incorpora alguns elementos da Reforma Sanitária, especialmente a participação comunitária, integração de práticas de saúde promocionais, de prevenção das doenças bucais e de assistência, organizadas em níveis de atenção. Ela recompõe a integralidade do ato odontológico, porém sua construção epistemológica ancora-se no campo odontológico. Assim, a odontologia integral nasce como alternativa ao projeto conservador oriundo da odontologia científica, incorporando três diretrizes: a simplificação, sem, contudo, chegar à excessiva simplificação e a desmonopolização, incorporando o pessoal auxiliar. Nesse caso, o ponto de partida permanece situado no campo odontológico, e essa proposta apresenta-se como síntese às propostas e projetos em curso. Qual a distinção entre a odontologia integral e a SBC, então?

Em primeiro lugar, é importante destacar que a SBC propõe um processo de desodontologização. A SBC parte inicialmente do questionamento do que seria o social. O social, geralmente apresenta-se como "um conjunto de condições relativas apenas a ambiente e à família” e, em geral, ignora-se "as relações dinâmicas e contraditórias que os homens estabelecem entre si ao trabalharem" (BOTAZZO et al., 1988, p. 30), que engloba os grupos e classes sociais.

Assim, para a SBC, o social corresponderia ao cenário, o espaço ou local onde os homens, os grupos e as classes sociais estabelecem relações entre si, e no qual a cultura, a ciência, a moral e todos os demais valores humanos são produzidos. É por isso que cada sociedade humana (cada povo), em cada época específica, produz coisas diferentes umas das outras: literatura, arquitetura, música, vestuários, alimentação, ciência, moral, hábitos etc. (BOTAZZO et al., 1988, p.30)

Nessa perspectiva, a questão principal consiste na inserção da análise do social a partir da sociedade e suas contradições. Há que se reconhecer a sociedade em sua totalidade social, uma leitura de classe. (BOTAZZO, 1994) Em segundo lugar, aparece nessa construção a crítica da abordagem sobre os problemas de saúde bucal da população, especialmente a cárie dental. Para a SBC, esta fora analisada historicamente a partir de uma abordagem que versa da unicausalidade à visão ecológica que produz. Por conseguinte, um conjunto de práticas odontológicas que se utilizam da prevenção e que se expressam nas propostas da época, notadamente a odontologia simplificada e odontologia integral e 
também a OPS. O resultado é a integração de práticas educativas, preventivas e curativas e a racionalização do trabalho odontológico pela simplificação.

A SBC propõe uma visão não ecológica da cárie, apresentando a abordagem da determinação social como alternativa para a compreensão do processo saúde doença bucal. Reforça essa tese ao apontar que, para a Odontologia ser integral, seria cada vez menos odontologia. Na perspectiva da determinação social, as práticas de saúde bucal envolveriam atividades clínicas e não clínicas, e, por esse motivo, não poderiam estar no campo odontológico e sim na saúde coletiva. Envolveria ações sobre as causas das doenças e suas distintas naturezas, sejam elas biológicas, econômicas, políticas ou sociais. Não se trata, portanto, de assistência odontológica cujo compromisso é com o individual e envolveria práticas de atenção à saúde bucal, abarcando práticas de saúde em outros espaços para além da boca. (BOTAZZO, 1992; 1994; BOTAZZO et al., 1988)

Seus argumentos estariam ancorados também na crítica ao conceito de saúde como "completo bem-estar" (OMS, 1946), apresentando a impossibilidade dessa perspectiva já que a saúde não poderia ser universal, uma vez que nem todos os grupos e classes possuem as mesmas condições materiais de existência. Isso porque a inserção de classes sociais define condições materiais de existência, formas de consumo, de produção relacionada à saúde, cuja assunção ao bem-estar físico, mental e social. Sendo assim, a abordagem admite que essa condição estaria condicionada, por sua vez, ao pertencimento do grupo social, que também define o nível de escolaridade, a ocupação, o acesso à informação, a participação nas decisões políticas, entre outras questões. Não oculta, portanto, as contradições existentes entre grupos e classes sociais. (BOTAZZO et al., 1988)

Esses argumentos, introduzidos pela leitura do processo saúde doença bucal, a partir da determinação social, colocam a politização do agente etiológico como elemento central da SBC, que consiste em considerar que a boca, como parte do indivíduo, é social e historicamente determinada. Nesse caso, a abordagem das práticas odontológicas deve contemplar a questão das classes sociais para a leitura das necessidades de saúde. Sabe-se que a cárie acomete, em geral, o sorriso dos proletários e a ciência odontológica leva à mutilação e aponta a necessidade de se politizar também a leitura dos dados e indicadores, politizando, por sua vez, a relação entre os números e a realidade social, o que requer novas organizações de serviços públicos odontológicos. (BOTAZZO, 1994) 
Assim, as práticas de saúde bucal pautadas na SBC vinculam-se ao campo de práticas coletivas em saúde, requerendo interdisciplinaridade e o envolvimento em ações de natureza coletiva, entendendo-as como expressão das relações políticas entre os vários atores sociais e envolvendo uma equipe de saúde bucal. Dizem respeito a atividades grupais em interação nos espaços socialmente reconhecidos - organizações e instituições que são áreas por excelência da desmonopolização do saber, ou seja, democratização do conhecimento e também representam espaços privilegiados do exercício da cidadania. Trata-se, portanto, de aproximar as práticas de saúde bucal às demais práticas de saúde e de superar a clientela escolar e a prestação de serviços públicos apenas para pobres. (BOTAZZO, 1992)

Segundo Botazzo (1994), as práticas de SBC seriam então "práticas direcionadas ao social como local de produção social das doenças bucais e suas tecnologias que visam curar o paciente na diminuição e controle dos processos mórbidos na dimensão coletiva”. (BOTAZZO, 1994· p. 57)

A SBC teria como objeto os determinantes sociais do processo saúde doença bucal, cuja análise tomaria a cárie como produto das contradições da sociedade que ilustra as diferenças entre classes. Seria também uma prática que envolveria distintas naturezas: políticas, econômicas, sociais e técnicas. Abarcaria práticas de assistência odontológica propriamente dita e não odontológicas, políticas, técnicas e sociais realizadas em espaços coletivos que seriam práticas de atenção à saúde bucal desenvolvidas, fundamentalmente, por uma equipe de saúde bucal. (SOARES, 2014)

\section{Saúde bucal coletiva: possíveis contribuições para a formulação de políticas de saúde bucal no Brasil}

Após compreender o percurso sobre os antecedentes, as respostas do Estado brasileiro, os aspectos históricos da gênese e as principais propostas da saúde bucal coletiva, cabe aqui identificar a existência ou não de possíveis contribuições para políticas nacionais de saúde bucal. Para isso, tomar-se-á como ponto de partida a Política Nacional de Saúde Bucal (PNSB) de 1989 e o Programa Nacional de Controle da Cárie Dentária (Precad) do mesmo período, passando pelos Procedimentos Coletivos (PC), a entrada da saúde bucal no Programa de Saúde da Família (PSF) e por fim, a PNSB, de 2004.

A PNSB e o precad foram lançados em 1989, na gestão de Vitor Gomes Pinto, na Divisão Nacional de Saúde Bucal do Ministério da Saúde. 
O objetivo geral da Política aprovada pela Portaria n. ${ }^{\circ}$ 613/GM, de 13 de junho de 1989, foi "proporcionar melhores níveis de saúde bucal à população brasileira e ampliar o acesso aos serviços odontológicos disponíveis". (BRASIL, 1989a) Os objetivos específicos da política tratavam de: (i) reduzir em 50\% a prevalência de cárie dental em crianças e adolescentes no prazo de 10 anos; (ii) combater as doenças periodontais, aumentando os índices de higidez em todas as faixas etárias; (iii) reduzir significativamente os índices de edentulismo e o número de extrações na população jovem e adulta; (iv) democratizar o acesso aos serviços odontológicos por meio do aumento da oferta, da atenção a grupos prioritários e da ampla participação da comunidade; (iv) estruturar uma rede nacional de serviços básicos em saúde bucal; (v) promover ações continuada de educação para a saúde bucal, de forma a nortear todas as atividades do setor; (vi) apoiar a formação de recursos humanos de nível superior, técnico e auxiliar compatíveis com o quadro epidemiológico, com a situação econômico social e com os padrões de crescimento populacional do país. (BRASIL, 1989a)

Os serviços deveriam se organizar também por prioridades. Serviços emergenciais para todos e precederiam os demais; em segunda prioridade, as ações preventivas e de educação em saúde; em terceiro lugar, "serviços recuperadores básicos" como atenção à cárie e doença periodontal, ao grupo de 6 a 12 anos; em quarta escala, estariam as especialidades básicas para atenção endodôntica, periodontia, protética, cirúrgica e ortodôntica para os grupos de 6 a 12 anos e 13 a 19 anos participantes de um sistema organizado; e, na quinta posição, serviços especializados de maior complexidade. (BRASIL, 1989a)

O Programa de Prevenção da cárie dentária (Precad) foi um subprojeto da primeira política e traz planos mais detalhados de como combater a cárie dentária na década de 1980. O documento tinha como objetivo geral reduzir em 10 anos 50\% da cárie dentária na população brasileira. A proposta era atingir o máximo de pessoas possíveis. Os subprogramas eram: a) fluoretação de água de consumo público; b) uso tópico de fluoretos; c) opção pela adoção de géis fluoretados aplicados em moldeiras na época das campanhas de vacinação para atingir o máximo de pessoas; d) vigilância e controle - normas para controle e registro de produtos; e) formação de recursos humanos; f) estudos epidemiológicos e biológicos. (BRASIL, 1989b)

Tanto a PNSB quanto o Precad sofreram influências da odontologia sanitária, assim como da OPS, com influência escandinava. Citam-se também os métodos preventivos de fluoretação em massa por via tópica e sistêmica, foco nos recur- 
sos humanos auxiliares, priorização de grupos e de serviços. Observa-se relação com a OPS nos métodos de vigilância e controle da cárie dentária, assim como nas normas para controle e registro de produtos, além de um foco bastante voltado para dentro da odontologia e suas medidas de enfrentamento possíveis à época dos problemas de saúde bucal da população brasileira. A democratização do acesso era direcionada para grupos prioritários, apesar da política citar os princípios finalísticos do SUS.

Os PC foram criados a partir da Portaria n. ${ }^{\circ}$ 184, de 9 de outubro de 1991, na gestão de Sérgio de Carvalho Weyne, na Coordenação de Saúde Bucal, passando a entrar em vigor em janeiro de 1992. Os PC foram criados para substituir os Tratamento Completados (TC) no repasse de recursos federais para estados e municípios. (CARVALHO et al., 2009) Existiam três tipos de PC:

“a) Procedimentos Coletivos I (PC-I) - Conjunto de procedimentos de promoção e prevenção em saúde bucal, de baixa complexidade, dispensando equipamentos odontológicos, desenvolvidos integralmente em grupos populacionais previamente identificados. Componentes: 1) Exame Epidemiológico - Levantamento epidemiológico realizado anualmente com objetivo de medir modificações no quadro epidemiológico das doenças bucais no grupo atendido; 2) Educação em Saúde - Atividades educativas realizadas trimestralmente, enfatizando os cuidados com a saúde bucal (dieta, desenvolvimento orofacial, aleitamento materno etc.); 3) Bochechos Fluorados - Realizados semanalmente, com solução de fluoreto de sódio a 0,2\%, ao longo do ano (mínimo de 25 aplicações); 4) Higiene Bucal Supervisionada - Compreende evidenciação de placa bacteriana e escovação supervisionada com pasta fluoretada, realizadas, no mínimo, a cada três meses, ao longo do ano, fornecendo a cada participante uma escova de dentes e um tubo de pasta fluoretada de 100 ou 90 g a cada três meses. b) Procedimentos Coletivos II (PC-II) - Consiste no conjunto de procedimentos constantes no PC-I acrescidos de: 1) Exame Clínico para Diagnóstico; 2) Terapêutica Intensiva com Flúor. c) Procedimentos Coletivos III (PC-III) - Componentes: Consiste no conjunto de procedimentos constantes nos códigos anteriores (PC-I e PC-II) acrescidos de: 1) Remoção de Cálculo e Polimento Dentário; 2) Escariação e Selamento de Cavidade, com Cimento Provisório; 3) Aplicação de Selantes; 4) Remoção de Raízes Residuais; 5) Aplicação de cariostático. (BRASIL, 1991; CARVALHO et al., 2009) 
Os PC apresentam uma forte relação com a OPS. Destaca-se o modelo de educação em saúde não centrado apenas nas escolas, mas nos grupos de pessoas em comunidades ou até mesmo nos serviços, assim como as ações de controle da cárie dentária de influência escandinava, mas ainda um forte apelo para ações de prevenção voltadas para o público infanto-juvenil.

A partir de 2000, com a Portaria n. ${ }^{\circ}$ 1.444, de 28 de dezembro deste ano, estabeleceu-se inclusão da saúde bucal no PSF e criação de incentivo financeiro para suas ações. No ano seguinte, a Portaria n. ${ }^{0}$ 267, de 6 de março de 2001, regulamentou a anterior e apontou as diretrizes de inclusão da saúde bucal na Estratégia Saúde da Família (ESF). A Cirurgiã Dentista (CD) que ocupava a coordenação nacional à época era Sônia Dantas. A reorganização das ações no âmbito da atenção primária previstas tratava dos princípios finalísticos e das diretrizes organizativas do SUS, seguindo os pressupostos da atenção primária abrangente discutida em Alma-Ata. Destacam-se as observações para as ações interdisciplinares, as atribuições dos profissionais com centralidade nas famílias, no território e nas competências culturais. Inácio (2003) aponta que a saúde bucal só se insere com política pública no SUS tardiamente, através da sua inclusão na ESF. A operacionalização das suas propostas apresenta as contribuições da SBC como aproximação das práticas das demais profissões de saúde, orientação cultural, relevância do território e os diversos cenários onde habitam os sujeitos; integração de práticas educativas, compatibilização entre atividades clínicas e não clínicas. Entretanto, como a política era voltada para a atenção básica, havia necessidades dos usuários que não eram atendidas como aquelas que demandavam procedimentos especializados.

Em 2004, é lançada a Política Brasil Sorridente, na gestão de Gilberto Pucca Jr., que expressa o projeto de movimentos contra-hegemônicos iniciados na década de 1980, conforme já referidos, pela democratização da saúde e pela SBC. As diretrizes da política são consoantes com os princípios do SUS, atuando em diferentes perspectivas de promoção da saúde, prevenção, cura e reabilitação a todos os cidadãos brasileiros, no atendimento de suas necessidades de saúde. Pioneiramente, essa política prevê serviços de atenção especializada em saúde bucal e a atuação em diferentes níveis de complexidade. Os princípios norteadores baseiam-se na gestão participativa, ética, acesso, acolhimento, vínculo e responsabilidade profissional. O documento apresenta o conceito ampliado de saúde como norteador das mudanças progressivas nos serviços e enfatiza que as ações do CD não devem ser restritas à assistência odontológica. 
(BRASIL, 2004) Destaca-se ainda uma influência da OPS quando se trata das ações de controle da cárie dentária, apesar da defesa de que não devam existir programas isolados para as distintas faixas etárias.

Após analisar os documentos das principais políticas de saúde bucal no período pós 1988 e a relação com os diversos movimentos e propostas no decorrer dos anos, cumpre questionar como a SBC vem balizando a implementação dessas políticas na atualidade?

\section{A SBC e a implementação da Política de Saúde Bucal na atualidade}

A publicação do livro Saúde bucal coletiva, por Vitor Gomes Pinto (2000), que manteve as características da antiga obra Odontologia social, significaria, segundo o próprio autor, apenas uma solicitação da editora, uma vez que a especialidade havia mudado de nome (SOARES, 2014), porém mantendo-a fiel também aos pressupostos da OPS. Poder-se-ia indagar se o uso do termo nessa perspectiva não seria apenas nas origens do espaço da SBC. Porém, uma breve exploração na literatura atual aponta a permanência da "velha" OPS nas práticas de SBC. (DIAS, 2006; DIAS; NARVAI; REGO, 2008)

Corrobora para essa situação o fato do cenário internacional não favorecer a pesquisa em SBC no Brasil. (MOYSÉS, 2008) As áreas de fomento da Federação Dentária Internacional são: placa dental, sistemas adesivos, prevenção da doença periodontal, resinas compostas, anestesia local, antibióticos, regeneração tecidual, prevenção de cáries, não cabendo, portanto objetos localizados no âmbito da SBC ao tempo em que reforça a OPS.

Esse cenário pode ser observado na publicação Saúde bucal coletiva: metodologia de trabalho e práticas (DIAS, 2006), coletânea com trabalhos de professores e profissionais de saúde bucal que, embora tenha pontos positivos acerca da consolidação de um subespaço cientifico da SBC, revela traços de permanência das odontologias anteriores nos ensaios que se apresentam no interior do trabalho. Nunes (2006) discute que a SBC sofreria da síndrome da "grande família”, com núcleos, parentes próximos, de segundo grau, terceiro grau, e outros, comportando subcategorias disciplinares, temáticas que por vezes ficam fora das ciências sociais, ampliando o escopo da SBC e fugindo, de certa forma, aos seus pressupostos de origem. Acrescenta-se que essa produção científica não tem se refletido nas práticas odontológicas realizadas nos serviços de saúde. Esta permanece subalternizada pelas práticas odontológicas tradicionais, tanto no âmbito privado como nos serviços públicos. 
Estudo realizado com grupo de estudantes que participaram de projetos comunitários, buscando sensibilização para o desenvolvimento de outras práticas distintas da prática clínica, concluiu que permanece entre eles o interesse para o trabalho voltado para o mercado de trabalho, apontando permanência do conservadorismo do campo odontológico e da hegemonia das suas práticas clínicas. (GONTIJO et al., 2009) Essa evidência reitera as dificuldades da SBC em atuar na formação do estudante, que carrega na sua prática as disposições do campo odontológico.

Há também que se notar, a partir da produção científica acerca das práticas, políticas e serviços de saúde bucal certo reforço à OPS. Nesse caso, embora haja todo esforço do grupo de agentes mobilizados politicamente, articulados ao referencial teórico e metodológico da saúde coletiva, e a proposta de um espaço novo vinculado a ele, ainda não foi capaz de mudar a lógica interna dos espaços sociais que a precederam, permanecendo certos habitus ou disposições inconscientes (BOURDIEU, 2009), inerentes a esses espaços.

Desse modo, a análise das práticas de SBC aponta a manutenção das contradições do campo odontológico, isto é, avanços tecnológicos com práticas eminentemente restauradoras, dificuldades de rompimento com a clínica tradicional e de incorporação da Equipe de Saúde Bucal (ESB). (MORETTI-PIRES; LIMA; MACHADO, 2011) Também se mencionam a inadequação do perfil dos profissionais de saúde bucal para a prática em SBC. (CALADO, 2002) O fato dessa concepção não se encontrar consolidada no Brasil, nem tampouco no âmbito internacional, confere à SBC um problema a ser resolvido.

Nesse caso, o conhecimento dessa concepção por uma comunidade pequena de dentistas constitui-se em um dos principais problemas para a manutenção do espaço social, tal como nas origens. (SOARES, 2014) Outras pessoas reproduzem o termo, filiam-se a ele, mas de fato não reconhecem as distinções entre ele e as "velhas odontologias". Permanecem velhos habitus que permitem a reprodução da OPS no Brasil. O desconhecimento da vertente política que exige a SBC faz dela, de certa forma, a velha OPS com nova denominação.

Embora se reconheça a produção teórica sobre SBC, esta não se constitui ainda como subcampo nem da saúde coletiva e nem da odontologia. A mais recente reforma educacional viabilizada pelas Novas Diretrizes Curriculares - Programa Nacional de Reorientação da Formação Profissional em Saúde 
(Pro-Saúde) ${ }^{3}$-, que promoveu incentivos na mudança dos vários currículos de odontologia, propiciaram a inserção da SBC em pequena parte de currículos de odontologia e, em alguns casos, "odontologia em saúde coletiva” ou saúde coletiva. Essa problemática foi investigada por Rodrigues, Saliba e Mormaz (2006), envolvendo a análise dos currículos de 123 cursos de odontologia que tinham formado pelo menos uma turma até 2003. Os autores observaram, na sua investigação, que a nomenclatura mais recorrente para designar a área de saúde coletiva é OPS.

Desse modo, constata-se que as preocupações com as mudanças das práticas odontológicas não ficaram no passado. É uma questão que continua em jogo no cenário atual. Corresponde à luta cotidiana que encampa a disputa hegemônica pelas práticas de saúde bucal no serviço público odontológico, já que a SBC tem o compromisso com os serviços públicos de saúde, com a justiça social, redução das iniquidades e com a manutenção do direito à saúde.

Reconhecendo essa problemática, alguns fundadores permanecem tematizando a SBC (BOTAZZO, 2013; BOTAZZO; CHAVES, 2014; NARVAI, 2008; NARVAI, 2001; NARVAI, 2006; FRAZÃO), tendo a publicação Diálogos sobre a boca, em 2013, um esforço de recuperação conceitual e da trajetória da SBC (BOTAZZO; CHAVES, 2014), bem como o texto intitulado "Saúde Bucal Coletiva: antecedentes e estado da arte", em livro de saúde coletiva, no qual aparece novos agentes tematizando a SBC. (BOTAZZO; CHAVES, 2014)

Outros movimentos vêm ocorrendo no subespaço científico nas décadas que sucederam a emergência da SBC, na direção de construção de um arcabouço teórico e metodológico para a prática da SBC. Várias obras têm sido publicadas com essa intenção. Em 2008, Samuel Moisés, Leo Kriger e Simone Moysés publicam coletânea que mescla discussões teóricas e experiências práticas, envolvendo vários autores citados neste trabalho, bem como fundadores da SBC. E recentemente, esse mesmo autor, em parceria com Paulo Goes, apresentou nova obra denominada Planejamento, gestão e avaliação em saúde bucal, também com a participação de vários agentes citados ao longo deste trabalho, bem como de alguns dos fundadores. (MOYSÉS; GÓES, 2012)

A resposta a essa questão talvez esteja no fato de a SBC ser ainda um espaço social ainda dominado sem autonomia relativa, bastante influenciado por ou-

O objetivo do programa é a integração ensino-serviço, visando à reorientação da formação profissional, assegurando uma abordagem integral do processo saúde-doença com ênfase na atenção básica, promovendo transformações na prestação de serviços à população. 
tros espaços, especialmente pelo campo odontológico e, muito embora se filie aos pressupostos da saúde coletiva, seu processo de reprodução aproxima-o cada vez mais da "odontologia" e de suas práticas sociais, notadamente aquelas orientadas pela OPS e odontologia sanitária. Sendo assim, um dos principais desafios da SBC, seria constituir-se como campo, ou seja, um espaço social relativamente autônomo e com um habitus comum que, por sua vez, subsidie teoricamente a aplicação prática nos serviços de saúde.

A recuperação da sua face política também deve compreender a pauta dos agentes desse espaço social. A formação de dentistas comprometidos com a saúde pública e com a mudança das práticas odontológicas tem sido preocupação de alguns fundadores. A ampliação de quadros, conformação de visão crítica e o compromisso com a prática de saúde bucal, "não odontológica”, pode ser um caminho para assegurar novos movimentos contra-hegemônicos. Assim, outro desafio dessa área constitui a formação de agentes comprometidos com o projeto de transformação das práticas odontológicas hegemônicas e constituição de novos "intelectuais orgânicos" a esse projeto de transformação social. (GRAMSCI, 1978)

Para tal, cabe recuperar a análise crítica das origens da SBC e a matriz política que se perdeu ao longo do tempo histórico, no período pós-Constituinte. Significa então reinserir-se no "processo" da Reforma Sanitária Brasileira, definido por Paim (2008) como o conjunto de atos políticos que se processam nas distintas conjunturas pós criação do SUS e na (re)politização da saúde de modo geral. Ademais, a configuração atual do campo odontológico e as relações políticas, econômicas e sociais que refletem a hegemonia das práticas de saúde bucal e a permanência da odontologia de mercado encontram-se entre os principais problemas da área hoje, cujo reforço às odontologias "alternativas" das décadas anteriores preservam a autonomia do campo odontológico. Essa hegemonia acaba sendo reforçada pela PNSB. Mas vale reconhecer que a SBC corresponde a um caso sui generis, um fenômeno brasileiro, genuíno e distinto das odontologias anteriores. (NARVAI, 1994; SOARES, 2014)

A fundação do grupo de trabalho de saúde bucal, no âmbito da Associação Brasileira de Saúde Coletiva, estreita as relações com a saúde coletiva brasileira e reafirma um compromisso histórico com o deslocamento do solo epistemológico do campo “odontológico" para o espaço da "saúde coletiva”, assim como a Reforma Sanitária Brasileira. 
Avanços foram identificados com a introdução da saúde bucal na ESF (BRASIL, 2000) e, especialmente, com a formulação de uma política própria de saúde bucal em 2004 (BRASIL, 2004), que expressa a principal reivindicação da SBC no seu nascedouro que consistia na entrada da saúde bucal no SUS. Isso significa a possibilidade de aplicação da SBC nos serviços de saúde, muito embora consultas à literatura mostrem a permanência das práticas do campo odontológico hegemônico. (CALADO, 2002; MORETTI PIRES; LIMA; MACHADO, 2011; SOARES et al, 2011)

A mesma política pode estar favorecendo a contradição e nesse caso reforçando o habitus higienista da OPS e a manutenção da odontologia de mercado que mantém o campo odontológico. $\mathrm{O}$ apoio às velhas concepções de OPS e odontologia sanitária, pela implementação das políticas de saúde bucal persistem, mesmo no cenário atual. Sendo assim, a SBC permanece nos dias atuais na luta pela hegemonia das práticas odontológicas tal como nasceu, disputando os rumos das políticas de saúde bucal. A reivindicação das origens do espaço da SBC que dizia respeito à entrada da odontologia no SUS foi alcançada com desenvolvimento das políticas e das práticas de saúde bucal no âmbito público. Todavia, essa inserção não garante a implementação dos princípios da SBC e da Reforma Sanitária Brasileira nas mesmas. (SOARES, 2014)

Cabe então sistematizar novos e velhos problemas que permanecem no espaço social ainda hoje, para além dos previamente relatados. Esses problemas significam entraves à consolidação de um campo de saberes e práticas de saúde bucal compatível com os princípios eticopolíticos da saúde coletiva e da Reforma Sanitária Brasileira, quais sejam: a corporação odontológica que limita os avanços em relação à formação da equipe de saúde bucal, incluindo a atuação plena do técnico em saúde bucal; a insuficiência teórica no espaço odontológico capaz de entender a questão do adoecimento bucal a partir da abordagem sobre os determinantes sociais, os quais levam à simplificação da epidemiologia em saúde bucal na análise de um processo social complexo como a cárie e outros problemas; a permanência nas práticas dos serviços de saúde bucal de conceitos antigos da odontologia privada presente na Fundação Serviços de Saúde Pública como tratamento iniciado e tratamento concluído, que reduz o acesso; bem como a conservação de ideias higienistas de décadas anteriores, baseado em campanhas sanitárias de escovação dentária supervisionada. Podese relacionar ainda como elemento importante na consolidação desse espaço que o esvaziamento do processo político que iluminou o movimento no perí- 
odo da sua origem precisa ser revitalizado, visto que a incorporação de novos agentes comprometidos com o projeto político da SBC e da Reforma Sanitária corresponde a uma premissa fundamental. Essa incorporação de novos agentes com habitus comuns compartilhados representa o maior dos desafios, já que a SBC exige, além da dimensão técnico-científica, a militância sociopolítica.

\section{Referências}

AROUCA, A. S. S. O Dilema preventivista: contribuições para a compreensão e crítica da medicina preventiva. São Paulo: UNESP, 2003.

BOTAZZO, C. Saúde bucal coletiva: um conceito em permanente construção. Saúde Atual, São Paulo, v. 1, p. 14-23, 1992.

BOTAZZO, C. A saúde bucal nas práticas coletivas de saúde. São Paulo: Editora do Instituto de Saúde, 1994. v.1.

BOTAZZO, C. Da arte dentária: um estudo arqueológico sobre as práticas dos dentistas. 1998. Tese (Doutorado em Saúde Coletiva) - Faculdade de Ciências Médicas, Unicamp, Campinas, 1998.

BOTAZZO, C. Diálogos sobre a boca. São Paulo: Hucite, 2013.

BOTAZZO, C. et al. Saúde bucal coletiva. 1988. (Texto elaborado como material de apoio para formação do ACD e THD, no projeto Larga escala).

BOTAZZO, C. Sobre a bucalidade: notas para a pesquisa e contribuição ao debate. Ciência e Saúde Coletiva, v. 11, n. 1, p. 7-17, jan./mar. 2006.

BOTAZZO, C.; CHAVES, S. C. L. Saúde bucal coletiva: antecedentes e estado da arte. In: PAIM, J. S.; ALMEIDA FILHO, N. Saúde Coletiva: teoria e prática. Rio de Janeiro: Medbook, 2014. p. 639-48.

BOURDIEU, P. Algumas propriedades gerais dos campos de produção cultural. In: BOURDIEU, P. As regras da arte: gênese e estrutura do campo literário. São Paulo; Companhia das Letras, 1976. p. 243-311.

BOURDIEU, P. O campo científico. In: ORTIZ, R. Pierre Bourdieu - Sociologia. São Paulo: Ática, 1994. p. 122-155.

BOURDIEU, P. O senso prático. São Paulo: Vozes, 2009.

BOURDIEU, P. Razões práticas: sobre a teoria da ação. Campinas, SP: Papirus, 1996.

BRASIL. Ministério da Saúde, Coordenação Nacional de Saúde Bucal, Departamento de Atenção Básica, Secretaria de Atenção à Saúde. Diretrizes da Política Nacional de Saúde Bucal. Brasília, DF, 2004.

BRASIL. Ministério da Saúde. Portaria $n^{\circ}$ 1444, de 28 de dezembro de 2000 . Cria o incentivo de saúde bucal destinado ao financiamento de ações e da inserção de 
profissionais dessa área no Programa de Saúde da Família (PSF). Diário Oficial [da] República Federativa do Brasil, Brasília, DF, 29 dez. 2000.

BRASIL. Ministério da Saúde. Portaria no 184, de 09/10/1991. Aprova a nova tabela de procedimentos Odontológicos constantes no anexo I dessa Portaria e respectivos códigos e preços para utilização em clientela do Sistema Único de Saúde - SUS. Diário Oficial [da] República Federativa do Brasil, Brasília, DF, 9 out. 1991.

BRASIL. Ministério da Saúde. Portaria 267, de 06/03/2001. Aprova normas e diretrizes de inclusão da saúde bucal na estratégia do Programa de Saúde da Família. Diário Oficial [da] República Federativa do Brasil, Brasília, DF, 6 mar. 2001.

BRASIL. Ministério da Saúde. Secretaria de Atenção à Saúde. Departamento de Atenção Básica. Coordenação Nacional de Saúde Bucal. Diretrizes da Política Nacional de Saúde Bucal. Brasília-DF, 2004.

BRASIL. Ministério da Saúde. Política Nacional de Saúde Bucal: princípios, objetivos, prioridades. Brasília, DF, 1989a.

BRASIL. Ministério da Saúde. Programa Nacional de Prevenção da Cárie Dentária. Brasília: DF, 1989b.

CALADO, G. S. A inserção da Equipe de Saúde Bucal no Programa Saúde da Família: principais avanços e desafios. Dissertação (Mestrado em Planejamento e Gestão de Sistemas e Serviços de Saúde) - Escola Nacional de Saúde Pública, Fundação Oswaldo Cruz, Fiocruz, Rio de Janeiro, 2002.

CARVALHO, L. A. C. et al. Procedimentos coletivos de saúde bucal: gênese, apogeu e ocaso. Saúde e Sociedade, São Paulo, v. 18, n. 3, p. 490-499, set. 2009.

CASOTTI, E. Odontologia no Brasil: uma (breve) história do pensamento sobre o ensino. Rio de Janeiro, 2009. 108 f. Tese (Doutorado Educação em Ciências e Saúde) - Núcleo de Tecnologias Educacionais em Saúde - NUTES, Universidade Federal do Rio de Janeiro, Rio de Janeiro, 2009.

CELESSE, R. K.; WARMLING, C. M. Produção bibliográfica brasileira de saúde coletiva em periódicos de saúde coletiva e de odontologia. Ciência \& Saúde Coletiva, Rio de Janeiro, v. 19, n. 6, p. 1921-1932, 2012.

CHAVES, M. M. Odontologia social. 3. ed. Rio de Janeiro: Artes Médicas, 1986.

(O) DENTISTA E O MUNDO DO TRABALHO. Movimento Brasileiro de Renovação Odontológica-MBRO. 19 jul. 2011.

Disponível em: <http://odentistaeomundodotrabalho.blogspot.com.br/2011/o7/movimentobrasileiro-de-renovacao.html>. Acesso em: 23. Jun. 2016.

DIAS, A. A. et al. Saúde bucal coletiva: metodologia de trabalho e práticas. São Paulo: Editora Santos, 2007.

DIAS, A. A.; NARVAI, P. C.; RÊGO, D. M. Tendências da produção científica em odontologia no Brasil. Revista panamericana de salud pública, Washington, D.C., v. 24, n. 1, p. 54-60, jul. 2008. 
DUMMETT, C. O. Retrospective on community and public health at the university of Southern Califórnia (1966-1976). Journal of the National Medical Association, Washington, D.C., v. 90, n. 5, p. 309-316, May 1998.

FERREIRA, R. C. Sistemas simplificados de espaço físico. Belo Horizonte: PUC-MG/ FINEP, 1985 .

FRAZÃO, P. Saúde bucal coletiva: metodologia de trabalho e práticas. Cadernos de Saúde Pública, Rio de Janeiro, v. 22, n. 11, nov. 2006.

FRAZÃO, P.; NARVAI, P. C. Saúde bucal no Brasil: muito além do céu da boca. Rio de Janeiro: Fiocruz, 2008.

FSESP. Normas técnicas de Odontologia Sanitária. ODONTOLOGIA, D. D. O. T.-S. Rio de Janeiro: Fundação Serviço Especial de Saúde Pública - Ministério da Saúde: 66 p. 1963.

GARCIA, J. C. La educación médica en la América Latina. Washington, D.C.: OPS/OMS, 1972. (Publicacion Científica, n. 255).

GOES, P. S. A; MOYSÉS, S. J. (Org.). Planejamento, gestão e avaliação em saúde bucal. São Paulo: Artes Médicas, 2012.

GONTIJO, L. P. T. et al. A saúde bucal coletiva na visão do estudante de odontologia: análise de uma experiência. Ciência \& Saúde Coletiva, Rio de Janeiro, v. 14, n. 4, p. 1277-85, 2009.

GRAMSCI, A. Cadernos do Cárcere. volume 2: os intelectuais, o principio educativo, jornalismo. Rio de Janeiro: Civilização Brasileira, 1978.

GRAMSCI, A. Cadernos do Cárcere. volume 3: Maquiavel. Notas sobre o Estado e a política. Rio de Janeiro: Civilização Brasileira, 1978.

GRAMSCI, A. Cadernos do Cárcere, volume 5: O risorgimento, notas sobre a história da Itália. Rio de Janeiro: Civilização Brasileira, 1978.

INÁCIO, J. A atenção à Saúde Bucal e o Sistema de Informações no município do Rio de Janeiro.. Dissertação (Mestrado em Saúde Pública) - Escola Nacional de Saúde Pública, Fundação Osvaldo Cruz, Rio de Janiero 2003.

MEIRA, A. J. de. Modelo de atenção simplificado a Escolares. Belo Horizonte, PUC-MG/ FINEP, 1985.

MENDES, E. V. A Reforma Sanitária e a Educação Odontológica. Cadernos de Saúde Pública, Rio de Janeiro, v. 2, n. 4, p. 533-552, out./dez. 1986.

MENDES, E.V.; MARCOS, B. Odontologia integral: bases teóricas e suas implicações no ensino, no serviço e na pesquisa odontológicas. A experiência de Departamento de odontologia da Pontifícia Universidade Católica de Minas Gerais. Belo Horizonte: PUCMG/FINEP, 1984.

MENDES, E. V. A reforma sanitária e a educação odontológica. Cadernos de Saúde Pública, Rio de Janeiro , v. 2, n. 4, p. 533-552, dec.1986 
MENDES, E. V. Odontologia Integral. Belo Horizonte. Ed. Fundação Mariana Resende Costa, 1985 .

MOYSÉS, S. J. O contexto atual para a pesquisa em saúde bucal coletiva: editorial. Caderno de Saúde Pública, Rio de Janeiro, v. 24, n.4, p. 718, abr., 2008.

MORETTI-PIRES, R. O.; LIMA, L. A. M.; MACHADO, M. H. Sociologia das profissões e percepção de acadêmicos e odontologia sobre o Agente Comunitário de Saúde em Saúde Bucal. Interface - Comunicação, Saúde, Educação, Botucatu, v. 15, n. 39, p. 1085-95, 2011.

NARVAI, P. C. Caminhos da odontologia sanitária à bucalidade. Revista de saúde pública, São Paulo, v. 40, p. 141-7, 2006.

NARVAI, P. C. Odontologia e saúde bucal coletiva. Rio de Janeiro: Hucitec, 1994.

NARVAI, P. C. Saúde bucal coletiva, bucalidade e antropofagia. Ciência \& Saúde Coletiva, Rio de Janeiro, v. 11, n. 1, p. 18-21, 2006.

NARVAI, P. C. Saúde bucal coletiva: um conceito. Odont. \& Soc., v. 3, n. 1/2, p. 47-52, 2001.

NARVAI, P. C.; ALMEIDA, E. S de. O sistema de saúde e as políticas de saúde na produção científica odontológica brasileira no período 1986-1993. Cadernos de Saúde Pública, Rio de Janeiro, v. 14, n. 3, p. 513-21, 1998.

NARVAI, P. C.; ALMEIDA, E. S. The national health system and health policies in the Brazilian dentistry literature, 1986-1993. Cadernos de Saúde Pública, Rio de Janeiro,v. 14, n. 3, p. 513-22, jul./set. 1998.

NARVAI, P. C.; FRAZÃO, P. Saúde Bucal no Brasil: muito além do céu da boca. Rio de Janeiro: Editora FIOCRUZ, 2008.

NICKEL, D. A.; LIMA, F. G.; DA SILVA, B. B. Modelos assistenciais em saúde bucal no Brasil. Cadernos de Saúde Pública, Rio de Janeiro, v. 24, n. 2, p. 241-246, 2008.

NUNES, E. D. Saúde bucal coletiva: a busca de uma identidade. Ciências \& Saúde Coletiva, Rio de Janeiro, v. 11, n.1, p. 37-9, 2006.

PAIM, J. S. Políticas de saúde no Brasil. In: ROUQUAYROL M. Z.; ALMEIDA FILHO, N. Epidemiologia e saúde. 6. ed., Rio de Janeiro: MEDSI. 2003. p. 587-603.

PAIM, J. S. Reforma sanitária brasileira: contribuição para a compreensão e crítica. Salvador: EDUFBA; Rio de Janeiro: Fiocruz, 2008.

PINTO, V. G. Saúde bucal coletiva. 4. ed. São Paulo: Editora Santos, 2000. 541p.

PINTO, V. G. Serviços básicos de saúde: a experiência do PIASS. A Saúde no Brasil., Brasília, DF, 1983.

QUEIROZ, M. G.; DOURADO, L. F. O ensino da odontologia no Brasil: uma leitura com base nas recomendações e nos encontros internacionais da década de 1960. História, Ciência, Saúde - Manguinhos, Rio de Janeiro, v.16, n. 4, p. 1011-26, 2009.

REBELO, M. A. B. Saúde bucal coletiva: implementando ideias, concebendo integralidade. Cadernos de Saúde Pública, Rio de Janeiro, v. 25, n. 4, p. 943-4, 2009. 
RODRIGUES, R. P. C. B.; SALIBA, N. A.; MOIMAZ, S. A. S. Revista ABENO, Londrina, v. 6, n. 1, p. 81-87, jan.-jun. 2006.

SAÚDE EM DEBATE. Revista do Centro Brasileiro de Estudos de Saúde, Rio de Janeiro, n. 18, mar./abr. 1986. Disponível em: <http://docvirt.com/asp/acervo_cebes. asp?Bib=SAUDEDEBATE\&PASTA=N.17+-+jul\&pesq=\&x=82\&y=12>. Acesso em: 23 jun . 2016.

SERRA, C. G. A saúde bucal como política de saúde análise de três experiências recentes: Niterói, Campinas e Curitiba. Rio de Janeiro, 1998. 204 p. Dissertação (Mestrado em Saúde Coletiva) - Instituto de Medicina Social, Universidade do Estado do Rio de Janeiro, Rio de Janeiro, 1998.

SILVEIRA FILHO, A. D. et al. Os dizeres da boca em Curitiba: boca maldita, boqueirão, bocas saudáveis. Rio de Janeiro: Centro Brasileiro de Estudos de Saúde; Curitiba: Secretaria Municipal de Saúde de Curitiba, 2002.

SOARES, C. L. M. A Constituição da Saúde Bucal Coletiva no Brasil. 2014. 180 f. Tese (Doutorado Saúde Pública) - Instituto de Saúde Coletiva. Universidade Federal da Bahia, Salvador, 2014.

SOARES, F. F. et al. Atuação da equipe de saúde bucal na estratégia saúde da família: análise dos estudos publicados no período 2001-2008. Ciências \& Saúde Coletiva, Rio de Janeiro, v.16, n.7, p. 3169-80, 2011.

TEIXEIRA, C. F; VILAS BOAS, A. L. Modelos de Atenção à Saúde: conservação ou mudança? In: PAIM, ALMEIDA-FILHO (Org.). Saúde Coletiva: teoria e prática. Rio de Janeiro: Editora: Med Book. 2014. p. 121-137.

UCHOA, H. Assistência odontológica no país: perspectivas 2. Cadernos de Saúde Pública, Rio de Janeiro, v. 1, n. 2, p. 263-269, Jun. 1985

WARMLING, C. M. Da autonomia da boca: um estudo da constituição do ensino da odontologia no Brasil. Porto Alegre, 2009. Tese (Doutorado em Educação) - Faculdade de Educação, Universidade Federal do Rio Grande do Sul, 2009.

WARMLING, C. M. Dos práticos à institucionalização da odontologia: um estudo histórico de saúde bucal de Blumenau. 2002. 126 f. Dissertação (Mestrado em Ciências Sociais) Centro de Ciência da Saúde, Universidade Federal de Santa Catarina, 2002. 